\title{
Comparison of Use of Isoflurane or Sevoflurane for Anaesthesia Induced by Mask in Calves
}

\author{
Selvinaz Yakan', Ozgur Aksoy² \& Celal Sahin Ermutlu²
}

\begin{abstract}
Background: Inhalation anaesthesia is an effective and reliable general anaesthesia method for inactivity, analgesia, and unconsciousness in extensive surgical procedures. Although widely used, especially in small animals, there are very few studies investigated the reliability and superiority of inhalation anaesthesia in surgical procedures for ruminants. This study intended to evaluate the anaesthetic effects of isoflurane and sevoflurane in different surgical cases with endotracheal intubation following the induction of anaesthesia using a calve-specific facemask, which is not yet a routine option in cattle.

Materials, Methods \& Results: The study was conducted on 14 calves, from new-born up to 3 months-old, that undergoing various surgical operations. The animals were divided into isoflurane and sevoflurane groups, and each group contained 7 animals. In all cases, atropine $(0.04 \mathrm{mg} / \mathrm{kg}$ was administered intramusculer as premedication before $15 \mathrm{~min}$ from anaesthesia induction. For induction, the anaesthetic agent was given at an inspiratory concentration of 3-5\% in the isoflurane group and at an inspiratory concentration of $5-7 \%$ in the sevoflurane group during 5 min via mask at 15 min after atropine administration. In both groups, endotracheal intubation was performed (about 1-3 min) after of general anaesthesia symptoms starting. At $5 \mathrm{~min}$ after induction, anaesthesia was continued at $1.5-3 \%$ in the isoflurane group and at $2.5-4 \%$ in the sevoflurane group during operation. The animals were monitored during anaesthesia and, anaesthetic effect, reaction of the calve, pronounced side effects, Heart Rate (HR), Systolic Arterial Blood Pressure (SABP), Diastolic Arterial Blood Pressure (DABP), Mean Arterial Blood Pressure (MABP), Respiration Rate (RR), Pulse Rate (PR), Arterial Oxygen Saturation $\left(\mathrm{SpO}_{2}\right)$ were recorded at before anaesthesia, the premedication period, 5, 15, 30, 45, 60, 75 and 90 min of anaesthesia. During anaesthesia, from the clinical parameters, mucosal capillary refilling time was evaluated by applying finger pressure to the oral mucosa. Mucous membrane color was determined by observing the oral mucosa. The time for palpebral reflex and swallowing reflex disappearance was measured and processed into individual forms. Anaesthesia induction and reanimation times were determined and recorded in the forms. After the operation, the return of the swallowing reflex and the time to stand up were recorded. During the operation, urination, defecation, salivation, vomiting, animal reactions, the shape and duration of the reamination period were recorded. In the isoflurane group anaesthesia induction was $3.71 \pm$ $0.28 \mathrm{~min}$, head movements started and came to the sterno- abdominal position at $4.57 \pm 0.36 \mathrm{~min}$, got up at $8.71 \pm 0.42$ min without assistance, meanwhile. In sevoflurane group, anaesthesia induction was $2.57 \pm 0.20$ min, head movements started and came to the sterno- abdominal position at $3.86 \pm 0.40 \mathrm{~min}$, the time to stand up was determined as $6.43 \pm 0.29$ min. During anaesthesia, HR, SABP, DABP, MABP, RR, $\mathrm{PR}, \mathrm{SpO}_{2}$ findings were within physiological acceptable limits in two groups. In terms of indicators, there were no obvious differences in either group. The results revealed no significant difference between groups during anaesthesia.

Discussion: The isoflurane and sevoflurane anaesthesia used in this study provided an adequate anaesthetic effect in calves characterized by adequate analgesia and muscle relaxation without any complications. The results of our study revealed that there was no significant difference between isoflurane and sevoflurane in calves. Both anaesthetic agents can be used safely for general anaesthesia in calves.
\end{abstract}

Keywords: mask induction, endotracheal intubation, isoflurane, sevoflurane, calve. 


\section{INTRODUCTION}

Inhalation anaesthesia is an effective and reliable method for inactivity, analgesia and unconsciousness in extensive surgical procedures [16,29,34]. Isoflurane and sevoflurane are considered the safest anaesthetic agents for inhalation anaesthesia [1,2,25,35].

The anaestesia induction and reanimation are fast because of the low blood gas solubility of isoflurane, a characteristic that shows that the side effects are minimal. It is easy to control the depth of anaesthesia with isoflurane, and the pulse remains stable. It inhibits respiration depending on the dose, but the tidal volume is affected rather than the respiration rate $[4,6,12,16,26]$.

Sevoflurane is an anaesthetic agent that can achieve a high alveolar concentration and can quickly equilibrate in blood and brain [7,28]. It reportedly causes faster and deeper anaesthesia as a result of cardiopulmonary effects compared to other inhalation anaesthetic agents [5,7,11]. Myocardial depression may occur, and arterial blood pressure and systemic vascular resistance may decrease depending on the dose $[7,15,34]$. Irritation of airways is not observed in both anaesthetic agents, and they are used for anaesthesia induction because of this feature [31,34]. In this study, mask induction was carried out using calf-specific facemask. The short time use of it for the induction of anaesthesia is highly practical, circumventing the need for injectable anaesthetics. The most effective and reliable method for the maintenance of inhalation anaesthesia is endotracheal intubation.

This study intended to evaluate the use of isoflurane and sevoflurane, which are not yet a routine option in cattle, in various surgical procedures.

\section{MATERIALS AND METHODS}

\section{Animals}

The study included 14 calves of a different breed, age, sex and body weight from new born up to 3-month-old, undergoing various surgical operations in Veterinary Faculty Animal Hospital at Kafkas University. The cases randomly were divided into 2 groups, the isoflurane, and the sevoflurane groups, and each group included 7 animals.

Anaesthesia procedures

Before inhalation anaesthesia for premedication, atropine (Atrol- $\left.\mathrm{R}^{\circledR}\right)^{1}$ was administered intamus- culer at dose of $0.04 \mathrm{mg} / \mathrm{kg}$. This application period was called the premedicaton period in the study. After 15 min, isoflurane (Isoflurane $\left.{ }^{\circledR}\right)^{2}$ was administered at inspiratory concentration of $3-5 \%$ via mask in isoflurane group, and sevoflurane (Sevorane $\left.{ }^{\circledR}\right)^{3}$ was administered at inspiratory concentration of 5-7\% via mask in sevoflurane group during 5 min for anaesthesia induction. This application period was called the induction period in the study. Endotracheal intubation was performed within 1-3 min on average to all cases at 5 min then induction period. To provide inhalation anaesthesia without excitation to all animals in both groups, the anaesthetic dose during the induction period was kept high at the beginning and the concentration of the anaesthetic was reduced after the appearance of deep anaesthesia symptoms. After the induction period, anaesthesia was continued at an inspiratory concentration of $1.5-3 \%$ in the isoflurane group and inspiratory concentration of $2.5-4 \%$ in the sevoflurane group.

During the operation, the animals maintained spontaneous breathing, and $100 \%$ oxygen was used as the carrier gas in the isoflurane and sevoflurane groups. The anaesthetic agent was cut off before the last few skin sutures were applied, and the spontaneous breathing of the animal was maintained with $100 \%$ oxygen. When the operation was completed, the anaesthetic device was disconnected from the endotracheal tube, and the animal was able to resume breathing normal atmospheric air. The endotracheal tube was removed with the onset of the swallowing reflex.

\section{Physiological monitoring}

Physilogical indicators, anaesthesia grades and cardiopulmonary parameters including of Heart Rate (HR), Systolic Arterial Blood Pressure (SABP), Diastolic Arterial Blood Pressure (DABP), Mean Arterial Blood Pressure (MABP), Respiration Rate (RR), Pulse Rate (PR), Arterial Oxygen Saturation $\left(\mathrm{SpO}_{2}\right)$ monitored using a monitor (Veterinary Monitor $\left.{ }^{\circledR}\right)^{4}$, and findings were recorded at before anaesthesia, premedication period, 5 (induction period), 15, 30, 45, 60, 75, and 90 min of study. To determine the cardiopulmoner effects of the administered anaesthetic agent, an appropriately sized cuff belongs to the monitör was placed on the Arterial axillaris on anterior limb, and HR, SABP, DABP, MABP were measured by oscillometry of the monitor and the values on the monitor screen were monitored. To measured RR, $\mathrm{PR}$ and $\mathrm{SpO}_{2}$ pulse oximetry probe of monitor was placed on the tongue 
and values were monitored. At the same time clinically, RR was monitored by observing the reservoir balloon and rib movements.

\section{Anaesthesia scores determination}

During anaesthesia, mucosal capillary refill time (intraoral mucosa was evaluated by applying finger pressure), palpebral reflex (determined by gently touching the medial or lateral angle of the eye), painful stimuli were applied with a 23 gauge needle to evaluate superficial and deep pain in the tail and limbs. Deep needle prick was assessed on a scale of 0 to 3 as reported by De Rossi et al. [9], and findings processed into individual forms. Anaesthesia induction and reanimation times were determined and recorded in the forms. After the end of the anaesthesia, the time to starting spontaneous breathing, the return of the swallowing reflex and the time to stand up were recorded.
Evaluation of anaesthesia was made according to the recommended scoring methods (Table 1) [10,13]. Scores of analgesia, sedative effects, muscle relaxation and posture were recorded for each time interval. The total score is the sum of the posture score, sedation score, analgesia score, skeletal muscle relaxation score, and needle prick response score.

\section{Statistical analysis}

All of the data obtained from the research, was evaluated using the Statistical Package for Social Sciences (SPSS-22) ${ }^{5}$ package program. The data were subjected to normality test. Non-parametric ones were made using Kruskal-Wallis test and normal ones were made using One-way ANOVA variance analysis method. $P<0.05$ was considered statistically significant. Values are given as mean \pm standard error (S.E).

Table 1. The criteria used for scoring after the anesthetic agent was administered in the groups.

\begin{tabular}{|c|c|}
\hline Criteria Score & Observation \\
\hline \multicolumn{2}{|l|}{ Posture scores } \\
\hline 0 & Normal \\
\hline 1 & Ataxic, but able to walk \\
\hline 2 & Complete prone, unable to walk \\
\hline 3 & Lateral recumbency, but able to move the tail or limb \\
\hline 4 & Complete lateral recumbency without motion \\
\hline \multicolumn{2}{|l|}{ Sedation scores } \\
\hline 0 & Normal \\
\hline 1 & Mild sedation (lateral recumbency, there is head motion and palpebral reflex) \\
\hline 2 & Moderate sedation (recumbent, head down, moderate eyelid reflex, bulbus oculi ventrally) \\
\hline 3 & Profound sedation (no motion, palpebral reflex disappeared, even mydriasis) \\
\hline \multicolumn{2}{|c|}{ Reflex response score ${ }^{\mathrm{a}}$} \\
\hline 0 & All reflexes are avaliable \\
\hline 1 & Decreased reflexes \\
\hline 2 & The swallowing reflex is considerably reduced and the endotracheal tube is easily inserted \\
\hline 3 & Palpebral and pedal reflexes are reduced or absent \\
\hline \multicolumn{2}{|l|}{ Analgesia scores ${ }^{\mathrm{b}}$} \\
\hline 0 & No analgesia and normal strong response to stimulus \\
\hline 1 & Mild analgesia and depressed response to stimulus \\
\hline 2 & $\begin{array}{c}\begin{array}{c}\text { Moderate analgesia and no response to superficial needle-prick stimulation of the skin in } \\
\text { response to stimulus }\end{array}\end{array}$ \\
\hline 3 & Complete analgesia and no response to insertion of the needle deep into the muscle layer \\
\hline \multicolumn{2}{|c|}{ Muscle relaxation score } \\
\hline 0 & Normal \\
\hline 1 & Mild relaxion in skeletal muscules \\
\hline 2 & Moderate relaxation in skeletal muscles \\
\hline 3 & The tone of her muscles decreased and relaxation occurred \\
\hline
\end{tabular}




\section{RESULTS}

Anaesthesia and recovery time

With induction of anaesthesia, signs of sedation, such as a decrease in movements, insensitivity to the environment, and a decrease in pain sensation, developed within $1 \mathrm{~min}$ in both groups. During the induction period, the palpebral reflex disappeared at $3.71 \pm 0.28$ min in the isoflurane group and at $2.57 \pm 0.20 \mathrm{~min}$ in the sevoflurane group, and this period was considered the beginning of anaesthesia induction. Rapid and regular induction of anaesthesia was provided in all cases in both groups. No adverse condition such as laryngospasm was encountered during endotracheal intubation in all cases in both groups. It was determined that the mucosal capillary refill time was 1-2 s before and during anaesthesia in calves that were administered isoflurane and sevoflurane anaesthesia. During anaesthesia, salivation, regurgitation and defecation were not observed in any of the patients in the isoflurane and sevoflurane groups. After discontinuation of the anaesthetic agent, at $4.57 \pm$ $0.36 \mathrm{~min}$ in isoflurane group cases, at $3.86 \pm 0.40 \mathrm{~min}$ in sevoflurane group, it was observed that head movements started and came to the sterno-abdominal position of the patients. All cases in the isoflurane group got up at 8.71 \pm 0.42 min without assistance, meanwhile, it was not observed that excitation or incoordination. In the sevoflurane group, the time to stand up was determined as $6.43 \pm 0.29 \mathrm{~min}$. No excitation or incoordination status was formed in this group, either. When the anaesthesia induction, the time to starting head movements, the time to reach the sterno abdominal position and the time to stand up were compared in the calves in both groups, the difference between them was statistically insignificant $(P>0.05)$ [Graph 1]. During anaesthesia, no animals died or showed inadequate anaesthesia for the operation.

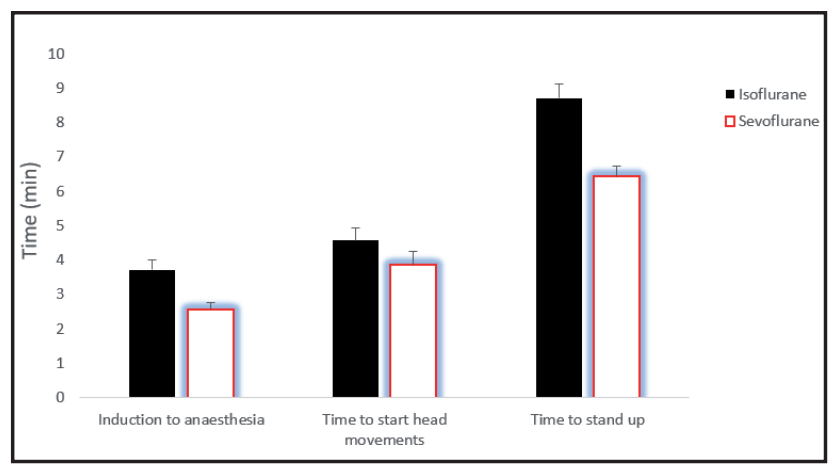

Graph 1. Introduction to anaesthesia, time to start head movements, time to reach sterno abdominal position and stand up time by groups.

\section{Changes in physiological parameters}

The results of cardiopulmonary parameters of groups were presented in Table 2. Before anaesthesia, HR was regular in the isoflurane and sevoflurane groups. The HR of two groups increased at premedication period and then decreased gradually. Though not statistically significant, the HR was higher in the isoflurane group than in the sevoflurane group. The differences in HR in comparison between groups, initial value, premedication period, $5,15,30,60,75$, 90 min were not statistically significant $(P>0.05)$, changes in the $45^{\text {th }}$ min were found to be statistically significant, $(P<0.05)$. In the isoflurane, no statistically significant difference was found between other measurement times with initial value in comparisons within-group $(P>0.05)$. In the comparisons between $5,60,75 \mathrm{~min}$ with premedication period min were not found statistically significant $(P>0.05)$, changes at 15, 30, 45, 90 min were statistically significant $(P$ $<0.05)$. In comparisons between the other times were not statistically significant difference $(P>0.05)$. In the sevoflurane, no statistically significant difference was found between other measurement times with initial value in comparisons within-group $(P>0.05)$. In the comparisons between other measurement times with premedication period, changes 5, 30, 75 and $90 \mathrm{~min}$ were not statistically significant $(P>0.05)$; in 15,45 and $60 \mathrm{~min}$ were found to be statistically significant $(P$ $<0.05)$ and, in comparison between other times were not statistically significant $(P>0.05)$. No significant change was observed in HR of groups during anaesthesia $90 \mathrm{~min}$.

Changes in SABP, DABP, MABP showed that isoflurane and sevoflurane minimally suppressed the cardiovascular system. According to baseline values SABP findings of both anesthetic agents showed reductions from that did not exceed physiological limits. There was no statistically significant difference between all measurement times in comparisons between groups $(P>0.05)$. In the isoflurane, no statistically significant difference was found between the all measurement results in the comparisons within-group $(P$ $>0.05$ ). In the sevoflurane, there was no statistical difference in comparison between premedication period, 5,75 and $90 \mathrm{~min}$ with initial value $\min (P>0.05)$, and there was statistically significant difference between the $15,30,45$ and $60 \mathrm{~min}(P<0.05)$, no statistically significant difference was found in comparisons be- 
tween other times $(P>0.05)$. Decreases in the DABP in the two groups were within the physiological limits, and these changes were not statistically significant $(P>$ $0.05)$. There was no statistically significant difference in comparisons both within-group and between-groups at all measurement times $(P>0.05)$. SABP, DABP and MABP values decreased slightly during anaesthesia. In terms of these indicators, there were no obvious differences in either group.

During inhalation anaesthesia, changes in RR remained within the physiological limits. The changes in $\mathrm{RR}$ and a depth exceeding physiological limits were corrected by artificial respiration through the reservoir balloon of the anaesthesia device, without any medical intervention. In findings RR, there was no statistically significant difference in comparisons both within-group and between-groups of isoflurane and sevoflurane at all measurement times $(P>0.05)$. Changes in PR in 2 groups were within physiological limits. In the comparisons between the groups, the difference between the 2 groups was statistically in significant at initial value, premedication period, 5, 15, 30, 45, 75, $90 \mathrm{~min}(P>0.05)$, the difference between the 60 min was statistically significant $(P$ $<0.05)$. There was no statistically significant difference between all measurement results in comparisons within-group of isoflurane and sevoflurane $(P>0.05)$. In $\mathrm{SpO}_{2}$, there was no statistically significant difference in comparisons both within-group and between-groups of isoflurane and sevoflurane at all measurement times $(P>0.05)$. During anaesthesia, it was observed that the mucous membrane color was normal in both isoflurane and sevoflurane groups.

\section{Anaesthesia scores}

Scores of analgesia, sedative effects, muscle relaxaion, and posture were recorded for each time interval. As shown in the second and third line in Table 3 , scores increased in both groups at 5 and $15 \min (P<$ $0.05)$ and then remained constant until administration was discontinued. Total scores in the sevoflurane group were slightly lower than in the isoflurane group, but were not significantly different. The analgesic effect of the isoflurane group was better than the sevoflurane group. However, no significant difference was observed between the groups $(P>0.05)$. Although the anesthetic effects were not statistically significant $(P>0.05)$, can be said that a more balanced anaesthesia occurred in the sevoflurane group.

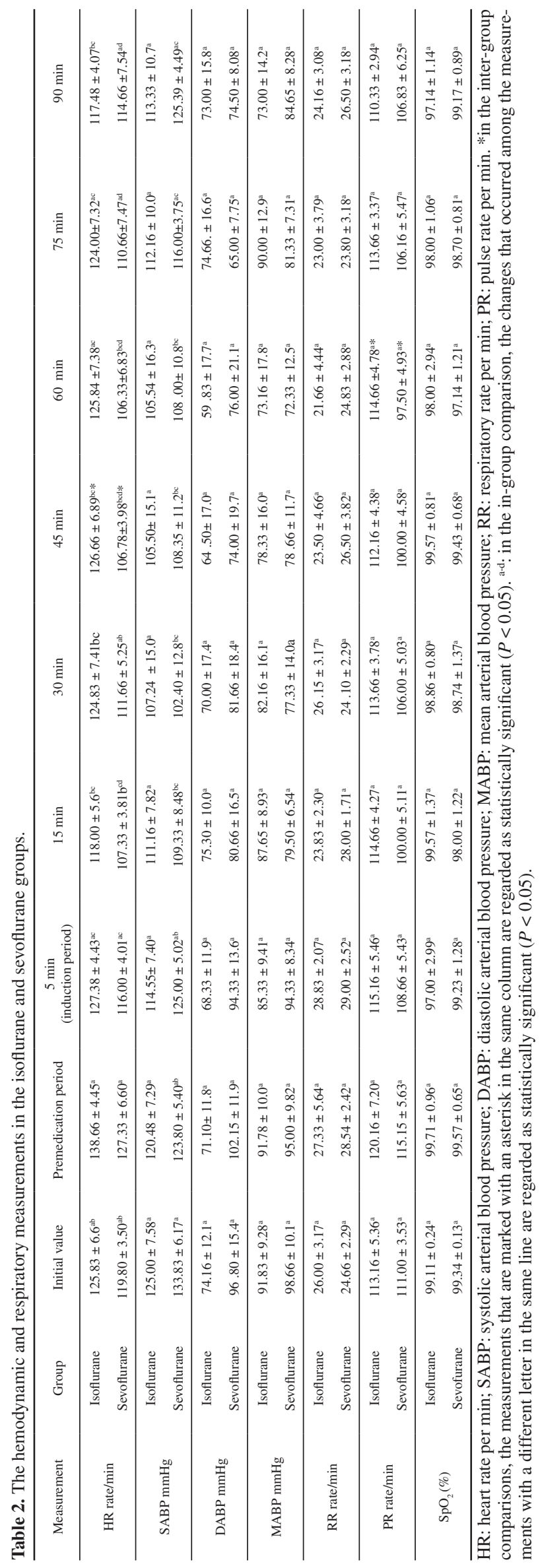


Table 3. Anaesthesia score table in total.

\begin{tabular}{ccc}
\hline Time $(\min )$ & Isoflurane & Sevoflurane \\
\hline 0 & $0.00 \pm 0.00^{\mathrm{a}}$ & $0.00 \pm 0.00^{\mathrm{a}}$ \\
5 & $10.57 \pm 0.75^{\mathrm{b}}$ & $9.57 \pm 2.63^{\mathrm{b}}$ \\
15 & $13.28 \pm 1.10^{\mathrm{b}}$ & $13.14 \pm 0.96^{\mathrm{b}}$ \\
30 & $14.14 \pm 0.59^{\mathrm{b}}$ & $14.28 \pm 0.28^{\mathrm{b}}$ \\
45 & $15.00 \pm 0.37^{\mathrm{b}}$ & $15.42 \pm 0.29^{\mathrm{b}}$ \\
60 & $14.71 \pm 0.64^{\mathrm{b}}$ & $14.28 \pm 0.60^{\mathrm{b}}$ \\
75 & $14.57 \pm 0.75^{\mathrm{b}}$ & $14.14 \pm 0.55^{\mathrm{b}}$ \\
90 & $0.50 \pm 0.34^{\mathrm{a}}$ & $0.00 \pm 0.00^{\mathrm{a}}$ \\
\hline
\end{tabular}

0 : before anaesthesia and premedication period. ${ }^{\mathrm{a}-\mathrm{b}}$ There is a statistically significant difference between values with different letters in the same column $(P<0.05)$.

\section{DISCUSSION}

General anaesthesia in calves is necessary for surgical interventions and diagnostic procedures. During general anaesthesia with injectable anaesthetics, tympani, regurgitation and aspiration pneumonia are likely to occur. Premedication with xylazine $\mathrm{HCl}$ may lead to complications such as airway blockages as a result of increased saliva. At the same time, injectable anaesthetics have undesirable effects such as respiratory depression, toxic effects on the heart, high metabolization, kidney and liver damage. The use of injectable anaesthetics in ruminants is not sufficiently reliable because of the inability to adjust the depth and duration of anaesthesia, the short duration of the anaesthetic effect, therefore maintenance doses are required, the rate of elimination from the body, and the long duration of emergence from anaesthesia [34]. Despite the ease of administration and the cost-effectiveness, the method of anaesthetic induction with injectable agents was not preferred in this study because of several disadvantages. Inhalation anaesthesia can be safely used to achieve controlled anaesthesia, especially in long interventions.

The effects of inhalation agents can be easily reversed, and the depth of anaesthesia can be controlled, and experiment results are minimally affected [17]. Although the method of inhalation anaesthesia is widely used, especially in small animals [16], there are only a few studies that have investigated the reliability and superiority of inhalation anaesthesia in ruminants for surgical procedures $[15,19,21]$. The goal of this study was to evaluate of anaesthesic effects of isoflurane and sevoflurane in different surgical cases with endotracheal intubation following the induction of anaesthesia with a calf-specific face mask, which is not yet a routine option in cattle.

Major problems that may be encountered during general anaesthesia in calves are excessive salivation, ruminal tympani, and regurgitation. Food intake should be prevented $8-12 \mathrm{~h}$ before the operation with the goal of reducing the content of rumen, reducing both regurgitation and breathing difficulties due to bloating $[18,20]$. A cuffed intubation tube should be used to prevent regurgitation [17]. The subjects included in this study were young calves. Therefore, hunger was not recommended. Complications such as tympani, excessive salivation, regurgitation, and dyspnea were not encountered in either group due to the use of cuffed endotracheal tubes. It has been reported that the administration of atropine prior to inhalation anaesthesia is necessary to provide ideal induction and to reduce the complications of general anaesthesia [12,30,31]. In our study, atropine $(0.04 \mathrm{mg} / \mathrm{kg}$ was injected intramusculer $15 \mathrm{~min}$ before the induction of anaesthesia. Conditions that may negatively affect inhalation anaesthesia, such as increased saliva or vomiting, were not observed. There was an increase in HR due to the administration of atropine in both groups. Although the HR decreased with the continuing of anaesthesia, HR in both groups was within physiologic acceptable limits.

There is a need for an effective and safe induction agent and a method for the intubation of patients and the initiation of inhalation anaesthesia [17,27]. Mask induction was performed using face masks that were specific to calves. Inhalation anaesthesia with this technique is very easy and practical, but the requirement for higher oxygen flow and creates difficulty for the control of anaesthesia is disadvantageous. When the mask does not fully cover the face, contamination of the operating room due to expired gases poses a risk to the health of personnel. The use of masks for the maintenance of anaesthesia is inconvenient, especially in ruminants, due to the disadvantages mentioned above. However, short-term use for induction purpose is quite practical and it is not possible for the mentioned disadvantages to occur. In our study, anaesthetic induction was induced with a mask. A face mask, which was fitted to the size of the calves, was used for induction. Anaesthetic induction in the isoflurane group was achieved with an inspiratory concentration of 3-5\% and was achieved in the sevoflurane group with an anaesthetic inspiratory concentration of 5-7\%. Isoflurane 
and sevoflurane reportedly provide rapid induction of anaesthesia because of their low blood gas solubilities. Sevoflurane is especially recommended for general anaesthesia in neonatal calves due to its rapid and regular induction. In our study, the time to anaesthesia induction was recorded in both groups, $2.57 \pm 0.20$ $\mathrm{min}$ in the sevoflurane group and $3.71 \pm 0.28 \mathrm{~min}$ in the isoflurane group. Sevoflurane reportedly provides rapid induction of anaesthesia because of its lower blood/gas solubility coefficient compared to isoflurane. According to our findings, sevoflurane-induced faster induction than isoflurane. Our findings are consistent with the literature [20,21,26,31].

Endotracheal intubation is the most effective method of safely maintaining anaesthesia after the induction period. In this method, the anaesthetic agent is administered directly to the lungs, and a high anaesthetic concentration is achieved rapidly. Therefore, anaesthesia occurs quickly. The control of anaesthesia is easy, with less oxygen and anaesthetic consumption, and effective artificial ventilation is supplied in the case of apnea $[16,26,28,30]$. The placement of an endotracheal tube requires knowledge and skills. In some studies [3,4,8,14,22,24,32], various complications have been reported due to user errors. Excessive efforts during intubation lead to damage to the larynx, pharynx, and soft palate of animals [3,8,31]. Meanwhile, laryngospasm may occur $[3,24,31]$ the balloon of the endotracheal tube is over-inflated, complications such as local ischemia, pressure necrosis, and tracheal rupture may occur in the tracheal mucosa $[3,4,14,24,31,33]$. In this study, no complications occurred in either group due to endotracheal intubation after mask induction.

The depth of anaesthesia can be evaluated by closely observing clinical symptoms and responses caused by surgical stimulation during operation. Today, clinical signs such as palpebral and corneal reflexes, pupil size and reaction to light, movement of the eyeballs, tearing, blood pressure, pulse, respiratory rate, depth, pattern, cardiovascular and respiratory response to the skin incision, sweating, skeletal muscle tone are evaluated and anaesthesia the depth is decided. The most important criterion here is the changes caused by the surgical incision in these symptoms [31,34]. In this study, anaesthesia scores in the isoflurane group showed a better analgesic appearance than the sevoflurane group, while painful stimuli were performed every 15 min with a 23 -gauge needle to evaluate superficial and deep pain in the tail and limbs. It has been stated that an increase of $20 \%$ or more in HR, SABP, DABP, MABP, RR, PR compared to baseline values during operation can be considered as an intraoperative pain symptom [23], but no increase in HR, SABP, DABP, MABP, RR, PR measurements was observed. No evidence of intraoperative pain in this regard, nor any other symptoms indicating pain, were found. As shown in Table 3, we found that the differences for $\mathrm{HR}$, SABP, DABP, MABP, RR, PR and $\mathrm{SpO}_{2}$ between the 2 anesthetics were not significant and were within physiological limits. This effect was due to the dose-dependent suppression of the cardiovascular and respiratory systems of inhalational anesthetics, so we initially very short time kept the anesthetic concentration high. Then we lowered the concentration.

Studies $[1,20,21,28]$ have shown that sevoflurane anaesthesia induction and recovery from anaesthesia is faster than isoflurane. At the end of the $90 \mathrm{~min}$ anaesthesia period in our study, we found that spontaneous respiration and the palpebral reflex in the sevoflurane group developed more quickly than in the isoflurane group when we evaluated recovery time from anaesthesia in our cases as a clinical sign. We think that this important advantage is related to the lower blood/gas solubility coefficient of sevoflurane compared to isoflurane. In our study, we determined the time to exit from anaesthesia as $8.71 \pm 0.42 \mathrm{~min}$ in the isoflurane group and $6.43 \pm 0.29 \mathrm{~min}$ in the sevoflurane group. The research of Yaygingul et al. [35] in their study where they applied isoflurane and sevoflurane anaesthesia in calves, found that the time to exit from anaesthesia was $30.80 \pm 1.89 \mathrm{~min}$ in the isoflurane group and $28.0 \pm 1.83 \mathrm{~min}$ in the sevoflurane group. This striking difference in our study, we attributed it to the induction of anaesthesia with inhalation anaesthesia.

\section{CONCLUSION}

The isoflurane and sevoflurane anaesthesia used in this study provided an adequate anaesthetic effect in calves characterized by adequate analgesia and muscle relaxation without any complications. The results of our study revealed that there was no significant difference between isoflurane and sevoflurane in calves. Both anaesthetic agents can be used safely for general anaesthesia in calves. 
MANUFACTURERS

${ }^{1}$ Sanovel Turkey. Istanbul, Turkey.

${ }^{2}$ Adeka İlaç Sanayi ve Ticaret A.Ş. Samsun, Turkey.

${ }^{3}$ Abbott Laboratuarları İth. İhr. ve Tic. Ltd. Şti. Istanbul, Turkey.

${ }^{4}$ Creative Medical Technology Holdings Inc. Phoenix, AZ, USA.

${ }^{5}$ SPSS Inc. Chicago, IL, USA.
Ethical approval. The study was approved by The Animal Local Ethics Committee (KAÜ, HAYDEK Number: 2010-081), Kafkas University.

Declaration of interest. The authors report no conflicts of interest. The authors alone are responsible for the content and writing of the paper.

\section{REFERENCES}

1 Apaydin N. \& Kibar M. 2008. Effects of isoflurane and sevoflurane anaesthesia on cardiovascular system during the experimental laparotomy of dogs. Journal of Health Sciences. 7(3): 162-167.

2 Apaydin N. \& Koc B. 2005. Comparison of the effects of isoflurane and sevoflurane anaesthesia on hemodynamic and biochemical parameters in dogs. Veteriner Cerrahi Dergisi. 11(1/4): 31-35.

3 Avki S., Yigitarslan K. \& Ozgel O. 2006. Comparison of airway size with some phenotypic parameters in Dalmation puppies: a practical method to estimate endotracheal tube size. Veterinary Anaesthesia and Analgesia. 33: 24-27.

4 Bateman L., Ludders J.W., Gleed R.D. \& Erb H.N. 2005. Comparison between facemask and laryngeal mask airway in rabbits during isoflurane anaesthesia. Veterinary Anaesthesia and Analgesia. 32(5): 280-288.

5 Canpolat I. 1992. Köpeklerde yeni bir inhalasyon anesteziği olan isoflurane ile halothane'nin karşılaştırılması. Journal of the Faculty of Veterinary Medicine, Firat University. 6: 1-2.

6 Cantalapiedra A.G., Villanueva B. \& Pereira L. 2000. Anaesthetic potency of isoflurane in cattle: determination of the minimum alveolar concentration. Veterinary Anaesthesia and Analgesia. 27(1): 22-26.

7 Cecen G., Topal A., Gorgul O.S. \& Akgoz S. 2009. The cardiopulmonary effects of sevoflurane, isoflurane and halothane anaesthesia during spontaneous or controlled ventilation in dogs. Journal of the Faculty of Veterinary Medicine, Ankara University. 56: 255-261.

8 Clutton R.E. \& Lawrence A. 1997. Armoured endotracheal tube-complications with use in pigs. Veterinary Anaesthesia and Analgesia. 24(2): 26-27.

9 De Rossi R., Almeida R.G., Medeiros U., Righetto F.R. \& Frazilio F.O. 2007. Subarachnoid butorphanol augments lidocaine sensory anaesthesia in calves. The Veterinary Journal.173(3): 658-663.

10 Dong J., Fan H. \& Li L. 2020. Comparison of anaeshetic of intravenous emulsified isoflurane and inhaled isoflurane in dogs. Kafkas Üniversitesi Veteriner Fakültesi Dergisi. 26 (5): 581-586.

11 Driessen B., Nann L., Benton R. \& Boston R. 2006. Differences in need for hemodynamic support in horses anesthetized with sevoflurane as compared to isoflurane. Veterinary Anaesthisa and Analgesia. 33(6): 356-367.

12 Duzgun O. \& Perk E.C. 1998. Köpeklerde ketamin indüksiyonu ile gerçekleştirilen isofluran anestezisi ve kan tablosuna etkileri üzerine araştırmalar. Journal of the Faculty of Veterinary Medicine, Istanbul University. 24(2): 379-401.

13 Fan H.G., Jiang S., Lin D.Q., Lu D.Z., Li L., Ji W. \& Li W.Z. 2014. Comparison of anaesthetic and analgesic effects of emulsified isoflurane used alone or combined with lidocaine and fentanyl in dogs. New Zealand Veterinary Journal. 62(3): 123-129.

14 Fujita M., Orima H., Simizu M., Motoyoshi S., Katayama M. \& Miyasaka K. 1991. Use of laryngeal mask airway in small animals. Journal of Veterinary Medical Science. 53(6): 1081-1082.

15 Greene S.A., Keegan R.D., Valdez R.A. \& Knowles D.K. 2002. Cardiovascular effects of sevoflurane in Holstein's calves. Veterinary Anaesthesia and Analgesia. 29(2): 59-63.

16 Gunay C. \& Unsaldi S. 2000. The effects of enflurane, isoflurane and propofol anaesthetics on blood parameters in dogs. Journal of the Faculty of Veterinary Medicine, Firat University. 14(1): 129-135.

17 Guzel O., Perk E.C., Aktas M. \& Devecioglu Y. 2005. Administration of inhalation anaesthesia in rabbits using the endotracheal intubation technique. Journal of the Faculty of Veterinary Medicine, Istanbul University. 3: 139-148.

18 Hedenqvist P., Roughan J.V., Antunes L., Orr H. \& Flecknell P.A. 2001. Induction of anaesthesia with desflurane and isoflurane in the rabbit. Laboratory Animals. 35(2): 172-179.

19 Hikasa Y., Hokushin S., Takase K. \& Ogasawara S. 2002. Cardiopulmonary, hematological, serum biochemical and behavioral effects of sevoflurane compared with isoflurane or halothane in spontaneously ventilating goats. Small Ruminant Research. 43(2): 167-178. 
20 Hikasa Y., Ohe N., Takase K. \& Ogasawara S. 1997. Cardiopulmonary effects of sevoflurane in cats: comparison with isoflurane, halothane, and enflurane. Research in Veterinary Science. 63(3): 205-210.

21 Hikasa Y., Okuyama K., Kakuta T., Takase K. \& Ogasawara S. 1998. Anaesthetic potency and cardiopulmonary effects of sevoflurane in goats: Comparison with isoflurane and halothane. Canadian Veterinary Journal. 62(4): 299306.

22 Hofmeister E.H., Trim C.M., Kley S. \& Cornell K. 2007. Traumatic endotracheal intubation in the cat. Veterinary Anaesthesia and Analgesia. 34(3): 213-216.

23 Kilic E., Yayla S., Kamiloglu A., Baran V. \& Ogun M. 2015. Effects of intrathecal administration of ketamine HCl in young calves: a clinical trial. Bulletin of the Veterinary Institute in Pulawy. 59: 155-159.

24 Mora S.S. \& Seymour C. 2011. An unusual complication o endotracheal intubation. Veterinary Anaesthesia and Analgesia. 38(2): 158-159.

25 Mutoh T., Nishimura R. \& Sasaki N. 2001. Effects of nitrous oxide on mask induction of anaesthesia with sevoflurane or isoflurane in dogs. American Journal of Veterinary Research. 62(11): 1727-1733.

26 Ozturk A. \& Altug M.E. 2007. Effects of repeated application of isoflurane and desflurane on electrocardiogram anaesthesia induction and recovery characteristics in rats. Bulletin of the Veterinary Institute in Pulawy. 51: 635-640.

27 Perk E.C., Duzgun O., Guzel O. \& Mutlu Z. 2004. Inhalation anaesthesia in swine. Journal of the Faculty of Veterinary Medicine, Istanbul University. 30: 47-59.

28 Read M.R., Read E.K., Duke T. \& Wilson D.G. 2002. Cardiopulmonary effects and induction and recovery characteristics of isoflurane and sevoflurane in foals. Journal of the American Veterinary Medical Association. 221(3): 393-398.

29 Reibold T.W. 2015. Ruminants. In: Grimm K.A., Lamont L.A., Tranquilli W.J., Greene S.A. \& Robertson S.A. (Eds). Lumb Jones Veterinary Anaesthesia and Analgesia. 5th edn. Ames: Blackwell, pp.912-927.

30 Rugh K.S., Zinn G.M., Paterson J.A. \& Thorne J.G. 1985. Inhalation anaesthesia in adult cattle. Laboratory Animal Science. 35: 178-181.

31 Topal A. 2005. Veteriner Anestezi. Bursa: Nobel \& Güneş, pp.107-128.

32 Touzot J.G., Stedman N.L. \& Trim C.M. 2005. The effects of two endotracheal tube cuff inflation pressures on liquid aspiration and tracheal wall damage in horses. Veterinary Anaesthesia and Analgesia. 32(1): 23-29.

33 Wiederstein I., Auer U. \& Moens Y. 2006. Laryngeal mask airway insertion requires less propofol than endotracheal intubation in dogs. Veterinary Anaesthesia and Analgesia. 33(4): 201-206.

34 Yakan S. \& Aksoy O. 2019. Comparison of the effects of isoflurane and sevoflurane general anaesthesia after induction by propofol on clinical and physiological measurements in calves. Acta Scientiae Veterinariae. 47: 1-10.

35 Yaygingul R., Belge A., Akin I., Unsal C., Bulut O. \& Kilic N. 2017. Comparison of clinical and hemodynamic effects of isoflurane and sevoflurane anaesthesia in calves. Acta Scientiae Veterinariae. 45: 1-10. 